\title{
Media Pembelajaran Matematika Berbasis Kartun untuk Menurunkan Kecemasan Siswa
}

\author{
Maghfira Maharani ${ }^{1}{ }^{*}$, Nanang Supriadi' ${ }^{1}$, Rany Widyastuti ${ }^{1}$ \\ 1Universitas Islam Negeri Raden Intan Lampung. Jalan Endro Suratmin, Sukarame, Bandar \\ Lampung35133, Indonesia. \\ *Corresponding Author. E-mail:: maghfiramaharani29@gmail.com
}

Received : 22-12-2017; Revised : 03-01-2018; Accepted : 29-01-2018

\begin{abstract}
Abstrak
Penelitian ini bertujuan untuk mengembangkan media pembelajaran matematika berbasis kartun untuk menurunkan kecemasan siswa. Produk yang dihasilkan adalah media pembelajaran matematika berbasis kartun dengan menggunakan Software Macromedia Flash untuk siswa kelas VII SMP pada materi aritmatika sosial. Penelitian ini menggunakan metode penelitian dan pengembangan model 4D yang dikemukakan oleh Thiagarajan yang terdiri dari 4 tahapan yaitu: (1) define atau pendefinisian; (2) design atau perancangan; (3) develop atau pengembangan dan (4) disseminate atau penyebaran. Teknik pengumpulan data yang digunakan adalah angket untuk respon siswa dan kecemasan siswa. Hasil penelitian adalah media pembelajaran matematika berbasis kartun yang layak digunakan sebagai media pembelajaran untuk menurunkan kecemasan siswa. kelayakan media pembelajaran yang dihasilkan dari ahli materi dan ahli media adalah valid dan layak digunakan sebagai media pembelajaran. Respon siswa terhadap media pembelajaran yang diperoleh pada uji kelompok kecil yaitu sangat menarik dengan skor rata-rata sebesar 3,52. Pada uji kelompok besar diperoleh kriteria kemenarikan yaitu sangat menarik dengan skor rata-rata sebesar 3,41. Tingkat kecemasan siswa setelah penggunaan media pembelajaran menurun, yaitu pada kategori kecemasan tinggi menurun dari $41 \%$ menjadi $0 \%$, kategori kecemasan sedang mengalami penurunan dari 35\% menjadi $24 \%$, kategori kecemasan rendah berubah dari $24 \%$ menjadi $76 \%$.
\end{abstract}

Kata Kunci : Kartun; Kecemasan; Pengembangan Media Pembelajaran.

\begin{abstract}
This research aims to developing a cartoon-based mathematics learning media to reduce students' anxiety. The resulting product is a cartoon-based mathematics learning media using macromedia flash software for grade VII students of SMP on social arithmetic material. This research uses $4 D$ research and development method, proposed by Thiagarajan consisting of 4 stages: (1) define or define; (2) design or design; (3) develop or development and (4) disseminate or disseminate. Researchers use qualitative and quantitative data analysis techniques. This research uses data collection techniques which are based on a questionnaire in the form of Likert scale for student response and student anxiety. The result of the research is a cartoon-based mathematics learning media which is suitable for learning media to decrease students' anxiety. The feasibility of instructional media resulting from material experts and media experts is valid and worthy of use as a medium of learning. The students' response to the learning media obtained in small group test is very interesting with the average score of 3.52. In the large group test obtained, the criteria of attractiveness is very interesting with an average score of 3.41. Levels of students' anxiety after the use of learning media have decreased, ie in the high anxiety category it has decreased from $41 \%$ to $0 \%$, in the medium anxiety category it has decreased fom $35 \%$ to $24 \%$, in the low anxiety category it has changed from $24 \%$ to $76 \%$.
\end{abstract}

Keywords: Development of Learning Media, Cartoon, Anxiety 


\section{PENDAHULUAN}

Pada era kemajuan ilmu pengetahuan di abad ini, pendidikan terus menjadi topik menarik untuk diperbincangkan oleh banyak pihak. Tanpa pendidikan, manusia yang hidup tidak akan tumbuh dengan kualitas yang baik (Kawiyah, 2015). Dictionary of Education menyebutkan bahwa proses seseorang dalam mengembangkan kemampuan yang dimilikinya seperti sikap serta bentuk-bentuk tingkah laku lainnya di dalam masyarakat tempat ia hidup, proses sosial tempat seseorang dihadapkan pada pengaruh lingkungan yang terpilih dan terkontrol khususnya sekolah, hingga perkembangan kemampuan sosial dan kemampuan individu yang dialami oleh dia optimum disebut pendidikan (Happy \& Widjajanti, 2014; Ihsan, 2005). Sekolah merupakan lembaga pendidikan formal yang mengajarkan generasi muda Indonesia dalam berbagai bidang kemampuan, salah satunya adalah matematika.

Matematika merupakan salah satu mata pelajaran yang wajib dilaksanakan pada setiap jenjang pendidikan mulai dari sekolah dasar sampai perguruan tinggi (Sulistyaningrum, Karyanto, \& Sunarno, 2015). Maka dari itu, hal tersebut menunjukkan bahwa matematika memiliki peranan penting bagi dunia pendidikan dan perkembangan teknologi. Bertolak belakang dengan peran penting matematika, faktanya masih banyak siswa yang menganggap matematika adalah pelajaran yang sulit (Putra, 2015; Putra, 2017). Hal ini diduga terjadi karena matematika bersifat abstrak dan harus memahami konsep sehingga siswa merasa jenuh dan bosan dalam belajar matematika. Disamping itu, dalam diri siswa masih timbul kecemasan dalam belajar matematika. Hurlok dalam (Susanti \& Rohmah, 2012) menjelasakan bahwa rasa cemas merupakan keadaan mental yang tidak enak berkenaan dengan sakit yang mengancamatau yang dibayangkan. Selain itu menurut Drajad dalam (Setyowati, Budiyono, \& Riyadi, 2013) kecemasan merupakan perasaan yang tidak menentu, panik, takut tanpa mengetahui sesuatu yang ditakutkan dan tidak dapat menghilangkan perasaan gelisah serta mencemaskan tersebut. Kecemasan yang berlebihan akan memberikan dampak yang tidak baik untuk seseorang, salah satunya menurunnya prestasi (Anita, 2014).

Berdasarkan hal ini penulis menyimpulkan bahwa agar pembelajaran matematika tersampaikan dengan baik dan diterima siswa maka dibutuhkan inovasi terbaru dalam belajar matematika yaitu dengan memanfaatkan media pembelajaran dengan guna untuk membangkitkan keinginan belajar matematika siswa dan mengurangi kecemasan siswa dalam belajar matematika. Simpulan ini diperkuat oleh seperti yang disampaikan (Sari, Farida, \& Putra, 2017) bahwa terdapat dampak positif dari pengguaan media pembelajaran dalam belajar matematika.

Karena pada dasarnya pengguanaan media pembelajaran yang menarik di sekolahan masih dikategorikan minim. Pengguanaan media pembelajaran masih sederhana yaitu berbahan dasar karton atau PowerPoint. Pembelajaran dengan media seperti itu kurang mendapat respon positif siswa dalam pembelajaran, siswa cenderung pasif (Purwanti, 2015). Selain itu, hasil yang diperoleh dari pembelajaran pun belum memuaskan (Ali, 2009). Kesan negatif matematika yang melekat pada matematika dapat dihilangkan dengan mengadakan inovasiinovasi dalam menyampaikan pembelajaran terkhusus di bidang matematika. Dalam hal ini penulis tertarik melakukan penelitian menembangkan media pembelajaran matematika berbasis kartun dengan memanfaatkan software aplikasi Macromedia Flash. 
Namun dalam penelitian ini akan dilakukan keterbaharuan dari penelitian sebelum yaitu penulis akan mengembangkan media pembelajaran matematika yang lebih ditekankan animasi kartun dengan tujuan agar dapat mengurangi kecemasan siswa serta meningkatkan motivasi siswa dalam belajar matematika.

\section{METODE}

Jenis penelitian ini adalah penelitian dan pengembangan (R\&D). Penelitian dan pengembangan ini menggunakan metode penelitian pengembangan perangkat 4D (Four D Model). Adapun tahapan yang akan dilakukan yaitu:

1. Tahap Pendefinisian (Define)

Mendefinisikan dan menetapkan syarat-syarat pengembangan media pembelajaran berbasis kartun merupakan tujuan yang akan dicapai pada tahap penelitian ini.

2. Tahap Perancangan (Design)

Tahap ini dilakukan untuk merancang media pembelajaran berbasis kartun. Tahap

3. Pengembangan (Develop)

Tahap ini dilakukan untuk menghasilkan media pembelajaran berbasis kartun.

4. Tahap Penyebaran (Disseminate)

Tahap terakhir pada penelitian ini adalah tahap penyebaran. Tahap diseminasi dilakukan untuk mempromosikan produk pengembangan agar bisa diterima pengguna, baik individu, suatu kelompok atau sistem.

Teknik pengumpulan data yang digunakan pada penelitian ini adalah wawancara dan angket skala likert dengan 4 jawaban. Penskoran yang digunakan dalam penilaian validasi ahli dapat dilihat pada Tabel 1.

\begin{tabular}{cc} 
Tabel 1. & Skor Penilaian Validasi Ahli \\
\hline Skor & Pilihan Jawaban Kelayakan \\
4 & Sangat Baik \\
3 & Baik \\
2 & Kurang Baik \\
1 & Sangat Kurang Baik \\
\hline
\end{tabular}

Sedangkan penskoran uji kemenarikan produk dapat dilihat pada Tabel 2.

\section{Tabel 2 Skor Penilaian Uji Coba

\begin{tabular}{cc}
\hline Skor & $\begin{array}{c}\text { Pilihan Jawaban } \\
\text { Kemenarikan }\end{array}$ \\
4 & Sangat Menarik \\
3 & Menarik \\
2 & Kurang Menarik \\
1 & Sangat Kurang Menarik \\
\hline
\end{tabular}

Skor penilaian total dalam analisa data dapat dicari dengan rumus berikut:

Dengan :

$$
\bar{x}=\frac{\sum_{i=1}^{n} x_{i}}{n}
$$

Keterangan :

$$
x_{i}=\frac{\text { jumlah skor }}{\text { Skor maks }} \times 4
$$

$\bar{x}=$ rata - rata akhir

$x_{i}=$ nilai uji operasional angket tiap siswa

$n$ = banyaknya siswa yang mengisi angket

Dalam pengkonversian skor kelayakan dan kemenarikan produk, digunakan pedoman berikut:

\section{Tabel 3 Kriteria Validasi}

\begin{tabular}{cc}
\hline Skor Kualitas & Kriteria Kelayakan \\
$3,26<\overline{\mathrm{x}} \leq 4,00$ & Valid \\
$2,51<\overline{\mathrm{x}} \leq 3,26$ & Cukup Valid \\
$1,76<\overline{\mathrm{x}} \leq 2,51$ & Kurang Valid \\
$1,00<\overline{\mathrm{x}} \leq 1,76$ & Tidak Valid \\
\hline
\end{tabular}

\section{Tabel 4 Kriteria untuk Uji Kemenarikan}

\begin{tabular}{cl}
\hline Skor Kualitas & \multicolumn{1}{c}{$\begin{array}{c}\text { Penyataan Kualitas } \\
\text { Aspek Kemenarikan }\end{array}$} \\
$3,26<\bar{x} \leq 4,00$ & Sangat menarik \\
$2,51<\bar{x} \leq 3,26$ & Menarik \\
$1,76<\bar{x} \leq 2,51$ & Kurang Menarik \\
$1,00<\bar{x} \leq 1,76$ & Tidak Menarik \\
\hline
\end{tabular}


Sedangkan untuk mengetahui penurunan kecemasan matematika siswa setelah diterapkan media pembelajaran, digunakan pedoman berikut:

\section{Tabel 5. Kriteria Deskripsi Kecemasan Siswa}

\begin{tabular}{llll}
\hline Skor & \multicolumn{2}{c}{ Kategori tingkat kecemasan siswa } \\
Angket & Tinggi & Sedang & Rendah \\
& $80 \geq x \geq 60$ & $40 \leq x<60$ & $20 \leq x<40$ \\
\hline
\end{tabular}

\section{HASIL DAN PEMBAHASAN}

Hasil penelitian dan pengembangan ini adalah sebuah media pembelajaran matematika berbasis kartun. Tahapan yang digunakan dalam penelitian dan pengembangan ini adalah metode penelitian dan pengembangan 4D. Tahapan-tahapannya yaitu:

\section{Tahap Pendefinisian (Define)}

Pada tahap ini diperoleh informasi bahwa dalam proses belajar guru sudah menggunakan media pembelajaran yaitu media pembelajaran nyata seperti kerangka balok dan kubus, penampilan PowerPoint dan lain sebagainya. Terkhusus untuk materi aritmatika sosial guru belum menggunakan media pembelajaran.

\section{Tahap Perancangan (design)}

Media yang akan dikembangkan yaitu media pembelajaran matematika berbasis kartun untuk menurunkan kecemasan siswa. Dalam tahap perancangan ini ada empat langkah meliputi penyusunan tes patokan awal berupa persiapan angket kecemasan, pemilihan media, pemilihan format, rancangan awal.

\section{Tahap Pengembangan (develop)}

Pada tahap ini media dibuat dengan menggunakan aplikasi Macromedia Flash 8. Selain itu pada tahap ini juga terdapat tahapan validasi ahli dan uji kelayakan produk. Setelah media di buat kemudian dilakukan penilaian oleh para ahli materi dan media. Setelah mendapat penilaian media ini dinyatakan valid dan layak digunakan sebagai media pembelajaran. Untuk hasil validasi dapat dilihat pada Tabel 6. dan Tabel 7.

\section{Tabel 6. Hasil Rata-rata Skor Validasi} Ahli Materi

\begin{tabular}{ccc}
\hline Rata-rata Skor & Kriteria & Keterangan \\
3,52 & Valid & Tanpa Revisi \\
\hline \multicolumn{3}{c}{ Tabel 7. Hasil Rata-rata Skor } \\
Validasi Ahli Media
\end{tabular}

Kelayakan dan kevalidan produk tidak terlepas dari masukan dan saran para ahli. Perbaikan-perbaikan yang dikembangkan berpedoman pada masukan-masukan serta saran yang diberikan oleh para ahli setelah media dinyatakan valid oleh para ahli maka tahap uji coba lapangan. Uji coba produk dilakukan dalam dua tahap yaitu uji kelompok kecil dan uji kelompok besar Hasil uji coba lapangan dapat dilihat pada Tabel 8.

Tabel 8. Hasil Rata-rata Angket Respon Siswa

\begin{tabular}{ccc}
\hline Kelas & Skor rata-rata & Kriteria \\
Skala Kecil & 3,52 & Sangat Menarik \\
Skala Besar & 3,41 & Sangat Menarik \\
& & \\
\hline
\end{tabular}


Pada uji coba skala kecil media pembelajaran kartun memperoleh respon siswa dengan kriteria sangat menarik dan skor rata-rata 3,52. Pada skala besar media ini memperoleh respon siswa dengan kriteria sangat menarik dan ratarata skor sebesar 3,41. Dalam hal ini dapat disimpulkan bahwa media pembelajaran ini sangat menarik untuk digunakan.

Selain untuk melihat respon siswa terhadap media pembelajaran yang dikembangkan, penelitian ini juga akan melihat penurunan kecemasan siswa saat belajar matematika ketika menggunakan media pembelajaran ini. Hasil penurunan kecemasan siswa dapat dilihat pada Tabel 9.

\begin{tabular}{cccc}
\multicolumn{4}{c}{ Tabel 9. Rekapitulasi Hasil } \\
Penurunan Klasifikasi Tingkat \\
Kecemasan \\
Tinggi & Kategori \\
Sedang & Rendah \\
& 12 & 10 & 7 \\
e-test & 0 & 7 & 22 \\
\hline st-test & 0 & &
\end{tabular}

\section{Tahap Penyebaran (Disseminate)}

Sebelum tahap ini dilakukan terdapat revisi produk yang dilakukan apabila terdapat kendala yang ditemukan pada saat uji coba produk. Akan tetapi pada penelitian ini tidak ditemukan kendala pada uji coba produk sehingga tidak perlu ada revisi kembali. Tahap terakhir dari penelitian dan pengembangan ini adalah tahap penyebaran yang dilakukan di SMPN 17 Bandar Lampung.

Hasil penelitian ini sama dengan hasil penelitian oleh (Masykur, Nofrizal \& Syazali, 2017) bahwa media pembelajaran matematika yang telah dikembangkan valid dan layak berdasarkan penilaian para ahli serta mendapatkan respon yang sangat menarik oleh siswa. Selain itu pembelajaran dengan menggunakan media pembelajaran berbasis macromedia flash dianggap para siswa menyenangkan sehingga siswa pembelajran matematika tidak terlalu menegangkan dan mencemaskan siswa.

\section{SIMPULAN DAN SARAN}

Kesimpulan yang diperoleh padapenelitian ini adalah: Kualitas media pembelajaran berbasis kartun yang telah dikembangkan memperoleh skor ratarata dari ahli materi sebesar 3,52 dan nilai rata-rata dari ahli media sebesar 3,57 dengan masing-masing pada kriteria Sangat Menarik. Respon siswa dalam pengembangan media pembelajaran berbasis kartun yang dilakukan sebanyak dua kali yaitu uji kelompok kecil dan uji kelompok besar masuk pada kategori sangat menarik dengan rata-rata skor pada uji kelompok kecil sebesar 3,52 dan uji kelompok besar sebesar 3,41. Sedangkan pada tingkat kecemasan siswa setelah penggunaan media pembelajaran menurun, yaitu pada kategori kecemasan tinggi menurun dari $41 \%$ menjadi $0 \%$, kategori kecemasan sedang mengalami penurunan dari 35\% menjadi 24\%, kategori kecemasan rendah berubah dari $24 \%$ menjadi $76 \%$. Berdasarkan hal ini media yang telah dikembangkan dapat menurunkan tingkat kecemasan siswa.

Berdasarkan kesimpulan yang telah dijelaskan diatas bahwa penulis menyarankan agar guru menggunakan media pembelajaran berbasis kartun dalampembelajaran matematika guna untuk menurunkan tingkat kecemasan siswa dalam belajar matematika.

\section{DAFTAR PUSTAKA}

Ali, M. (2009). Pengembangan media pembelajaran interaktif mata kuliah medan elektromagnetik. Jurnal Edukasi Elektro, 5(1).

Anita, I. W. (2014). Pengaruh kecemasan matematika (mathematics anxiety) terhadap kemampuan koneksi matematis siswa SMP. Infinity Journal, 3(1), 125-132. 
Happy, N., \& Widjajanti, D. B. (2014). Keefektifan PBL ditinjau dari kemampuan berpikir kritis dan kreatif matematis, serta self-esteem siswa SMP. Jurnal Riset Pendidikan Matematika, 1(1), 48-57.

Ihsan, F. (2005). Dasar-dasar kependidikan. Jakarta: Rineka Cipta.

Kawiyah, S. (2015). Pengembangan Perangkat Pembelajaran Matematika Berbasis Saintifik untuk Meningkatkan Kemampuan Pemecahan Masalah dan Prestasi Belajar Siswa. Pythagoras: Jurnal Pendidikan Matematika, 10(2), 201210.

Purwanti, B. (2015). Pengembangan Media Video Pembelajaran Matematika dengan Model Assure. Jurnal Kebijakan Dan Pengembangan Pendidikan, 3(1).

Putra, F. G. (2015). Eksperimentasi Model Pembelajaran Kooperatif Tipe Teams Games Tournament (TGT) Berbantuan Software Cabri 3d di Tinjau dari Kemampuan Koneksi Matematis Siswa. Al-Jabar: Jurnal Pendidikan Matematika, 6(2), 143154.

Putra, F. G. (2017). Eksperimentasi Pendekatan Kontekstual Berbantuan Hands On Activity (HoA) Terhadap Kemampuan Pemecahan Masalah Matematik. Al-
Jabar: Jurnal Pendidikan Matematika, 8(1), 73-80.

Sari, A. U., Farida, F., \& Putra, F. G. (2017). Pengembangan Media Pembelajaran berbantuan Web dengan Pendekatan Etnomatematika pada Pokok Bahasan Bangun Ruang Sisi Datar. Prosiding Seminar Nasional Matematika dan Pendidikan Matematika, 1(1), 209-214.

Setyowati, A., Budiyono, B., \& Riyadi, R. (2013). Eksperimentasi Model Pembelajaran Kooperatif Tipe Teams Games Tournament (TGT) dan Fan-N-Pick pada Prestasi Belajar Matematika Ditinjau dari Kecemasan Pada Matematika Siswa SMP Negeri Di Kabupaten Magelang. Sulistyaningrum, D. E., Karyanto, P., \& Sunarno, W. (2015). Pengembangan Modul Berbasis Model Pembelajaran Arias untuk Memberdayakan Motivasi dan Berpikir Kritis Siswa pada Materi Ekosistem. INKUIRI Jurnal Pendidikan IPA, 4(1), 104-116.

Susanti, D. W., \& Rohmah, F. A. (2012). Efektivitas musik klasik dalam menurunkan kecemasan matematika (math anxiety) pada siswa kelas XI. HUMANITAS (Jurnal Psikologi Indonesia), 8(2), 129-142. 